\title{
THERMODYNAMIC AND TRANSPORT PROPERTIES OF TERNARY MIXTURES OF ETHANOL + 1, 2-PROPANEDIOL + CYCLOHEXANONE AT 308.15K, 318.15K AND FT-IR STUDY
}

\author{
Johnson.S*1, Rose Venis. $A^{2}$, Rosario Rajkumar $X^{3}$ \\ ${ }^{1,2 \& 3} P G$ and Research Department of Chemistry, St. Joseph's College (Autonomous) Tiruchirappalli, \\ Tamil Nadu - 620002 (India) \\ Johnson200672@gmail.com
}

\begin{abstract}
Density $(\rho)$ and viscosity $(\eta)$ for ternary liquid mixtures of ethanol $+1,2$ propanediol + cyclohexanone were measured at 308.15 and $318.15 \mathrm{~K}$ over the entire range of composition. From the measured data, Excess volume $\left(V^{E}\right)$, Deviation in viscosity $(\Delta \eta)$ and excess Gibbs free energy of activation of viscous flow $\left(\Delta G^{*}\right)$ were calculated. The results were fitted with Redlich-kister's type polynomial equation and standard deviation between calculated and experimental excess parameter have been determined. Further, Heat of mixing and FT-IR spectrum are studied at equimolar concentration. The results provide information on the interaction of molecules in the pure liquids as well as in the ternary liquid mixtures.
\end{abstract}

Key words: Excess volume, Deviation in viscosity, Excess Gibbs free energy of activation of viscous flow, Heat of mixing, FT-IR spectra.

\section{INTRODUCTION}

Liquid mixtures are widely used in processing and product formation in many industrial applications, such as concerning heat transfer, mass transfer and fluid flow. Thermodynamic and transport properties of liquids provide useful information about physical and chemical force acting between the molecules have the same substance in pure liquids and molecules have the different substance in liquid mixtures.

When two liquids were mixed together the resulting changes in physical and thermodynamic properties can be considered as sum of several contribution due to volume change, change in energy, change in molecular orientation etc. The density $(\rho)$ and viscosity $(\eta)$ of binary and ternary liquid mixtures are important from practical and theoretical point of view to understand the liquid theory.

The excess thermodynamic functions also provide information on the nature of molecular interaction between the molecules [1-3]. This work involves systematic studies on thermodynamic properties of ternary liquid mixtures. The present work is focused on the qualitative explanation of the influence of molecular volumetric data of ternary mixtures containing Ethanol, 1,2-propanediol and cyclohexanone. Ethanol (1) is considered as first component and second component is 1,2-propanediol (2) and cyclohexanone (3) as the third component. Moreover a survey of literatures has shown that no experimental ternary liquid mixtures on ethanol and 1,2-propanediol with cyclohexanone were reported earlier.
Ethanol molecule is polar and self associated through hydrogen bonding of their hydroxyl group [4]. Generally alkanols are used as fuels, perfumes, cosmetics, paints, vanishes, drugs, explosives, fats, waxes, resins, plastics and rubber, detergents etc. [5]. Alkanediols are self associated compounds through intermolecular hydrogen bonding with other molecules and also intramolecular hydrogen bonding within their molecules. Cyclohexanone is expected to exhibit dipole-dipole interaction in pure state because of its fairly high dipolmoment. However the association between cyclohexanone molecules is weak and does not compete with high degree of association between alcohol molecules.

\section{EXPERIMENTAL METHODS}

The chemicals used in the present study are analytical grade (Merck) and furthur purified by standard methods [6, 7]. Before use, the chemicals were dried by suitable drying agents to remove the water content, if any. The mixtures were prepared by knowing mass and were kept in special air tight glass stoppered conical type bottles to avoid evoporation. The weighing measurements were performed on a shimasdzu Auy 220 Japan electronic digital balance with precision of \pm 0 . $0001 \mathrm{~g}$.

The density of pure liquids and their liquid mixtures were measured by using special type specific gravity bottle of $10 \mathrm{ml}$ capacity with an accuracy $\pm 0.0001 \mathrm{~g}$. The specific gravity bottle containing solution was immersed in a constant temperature water bath (Guna company) measured at 308.15 and $318.15 \mathrm{~K}$. Each reported values are the average of at least three measurements. 
The viscosity of pure liquids and their liquid mixtures were measured by using an ostwald viscometer of $10 \mathrm{ml}$ capacity. The viscosities at temperature 308.15 and $318.15 \mathrm{~K}$ were measured. The time given to attain thermal equallibrium for the content of viscometer was $15 \mathrm{~min}$. The time of flow was measured with an accurate stop watch which is capable of measuring time to within $0.01 \mathrm{~s}$. Three sets of reading for the flow time were taken and the average values were taken for each pure liquids and liquid mixtures.

Heat of mixing of ternary liquid mixtures were measured with calorimeter (Dewar flask) at equimolar concentration.
IR study

IR spectra for pure liquids and equimolar liquid mixtures were recorded by Brucker FT-IR, Alpha-E Germany.

\section{RESULTS AND DISCUSSION}

Comparison of experimental density $(\rho)$ and viscosity $(\eta)$ values with literature values for pure Ethanol, 1,2 propanediol and cyclohexanone are presented in Table-1. There is good agreement with literature values at 308.15 and $318.5 \mathrm{~K}$ temperature for both density $(\rho)$ and viscosity $(\eta)$.

Table - 1: Comparison of density $(\rho)$ and viscosity $(\eta)$ valves with literature values of pure liquids at 308.15 and $318.15 \mathrm{~K}$

\begin{tabular}{|c|c|c|c|c|c|}
\hline \multirow{2}{*}{$\begin{array}{l}\text { Name of the } \\
\text { components }\end{array}$} & \multirow{2}{*}{$\begin{array}{c}\text { Temperature } \\
\text { K }\end{array}$} & \multicolumn{2}{|c|}{$\begin{array}{l}\text { Density } \\
\rho / \mathrm{g} \mathrm{cm}^{-3}\end{array}$} & \multicolumn{2}{|c|}{$\begin{array}{l}\text { Viscosity } \\
\eta / \text { mPa.s }\end{array}$} \\
\hline & & Expt & Lit & Expt & Lit \\
\hline \multirow[t]{2}{*}{ 1. ETHANOL } & 308.15 & 0.7766 & $0.7765[8]$ & 0.9138 & $0.8970[9]$ \\
\hline & 318.15 & 0.7652 & $0.7684[10]$ & 0.7678 & $0.8714[11]$ \\
\hline \multirow[t]{2}{*}{ 2. 1,2 PROPANEDIOL } & 308.15 & 1.0256 & $1.0251[12]$ & 21.3250 & $25.2200[13]$ \\
\hline & 318.15 & 1.0199 & $1.0180[14]$ & 12.7391 & $12.7800[15]$ \\
\hline \multirow[t]{2}{*}{ 3. CYCLOHEXANONE } & 308.15 & 0.9290 & $0.9306[16]$ & 1.3140 & $1.6562[17]$ \\
\hline & 318.15 & 0.9237 & $0.9225[18]$ & 1.0640 & $1.3700[19]$ \\
\hline
\end{tabular}

The densities $(\rho)$ and viscosities $(\eta)$ of given ternary mixtures containing namely Ethanol and 1,2-propanediol with cyclohexanone at 308.15 and $318.15 \mathrm{~K}$ are presented in Table $2 \& 3$ which also includes the values of excess thermodynamic function viz, Excess volume $\left(\mathrm{V}^{\mathrm{E}}\right)$, deviation in viscosity $(\Delta \eta)$, molar volume $\left(\mathrm{V}_{\text {mix }}\right)$ and excess Gibbs free energy of activation of viscous flow $\left(\Delta \mathrm{G}^{*} \mathrm{E}\right)$. It can be seen that variation of density $(\rho)$ and viscosity $(\eta)$ with composition of ternary mixture is non-linear which indication the presence of molecular interactions [20,21].

The excess volume of the given ternary liquid mixtures was evaluated from the molar volumes of mixtures and that of its pure components $\mathrm{V}_{1}, \mathrm{~V}_{2}$ and $\mathrm{V}_{3}$ using the equation (1) [22].

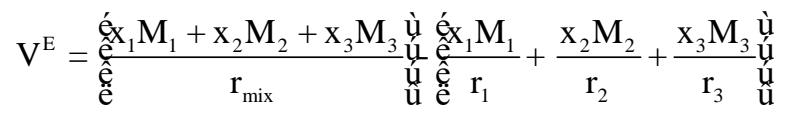

Viscosities of ternary liquid mixtures and their pure liquids were calculated by using the following equation (2) [22].

$$
\eta=(\text { At }-\mathrm{B} / \mathrm{t}) \times r
$$

where A and B are characteristic constant, t-is the time flow, $\rho$ - is the density.

The molar volumes $\left(\mathrm{V}_{\text {mix }}\right)$ of mixtures and their pure liquid components were calculated from the measured density $\left(\rho_{\text {mix }}\right)$ and pure liquids (1,2 and 3) $\rho_{1}, \rho_{2}$ and $\rho_{3}$ using the following equation (3) [23].

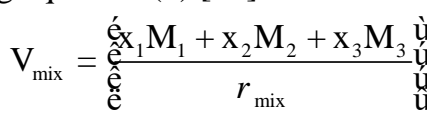

where $x_{1}, x_{2}$ and $x_{3}$ are the molefraction of the individual components of ternary liquid mixtures respectively, $\mathrm{V}_{1}$ is $\mathrm{M}_{1} / r_{1}, \mathrm{~V}_{2}$ is $\mathrm{M}_{2} / r_{2}$ and $\mathrm{V}_{3}$ is $\mathrm{M}_{3} / r_{3}, \mathrm{M}_{1}, \mathrm{M}_{2}$ and $\mathrm{M}_{3}$ are the molecular weight of the components 1,2 and $3, \rho_{1}, \rho_{2}$ and $\rho_{3}$ densities of the pure components 1,2 and 3 of the termary liquid mixtures.

The deviation in viscosity $(\Delta \eta)$ of the ternary liquid mixtures was calculated from the observed viscosity of mixtures $\left(\eta_{\text {mix }}\right)$ and that of its pure components using the equation (4) [24].

$\Delta \eta=\eta_{\text {mix }}-\left\{x_{1} \eta_{1}+x_{2} \eta_{2}+x_{3} \eta_{3}\right\}$

where $\eta_{\text {mix }}$ is the viscosity of termary liquid mixtures and $\eta_{1}$, $\eta_{2}$ and $\eta_{3}$, are the viscosity of pure components respectively 1,2 and $3, x_{1}, x_{2}$ and $x_{3}$ are the mole molefraction of the components 1,2 and 3 .

Excess Gibbs energy of activation of viscous flow $\left(\Delta \mathrm{G}^{*} \mathrm{E}\right)$ for the liquid mixtures were computed from the following equation (5) [25].

$\Delta \mathrm{G}^{* \mathrm{E}}$

RT $\left(\ln \left(\eta_{\text {mix }} \mathrm{V}_{\text {mix }}\right)\right)-\left[\mathrm{x}_{1} \ln \left(\eta_{1} \mathrm{v}_{1}\right)+\mathrm{x}_{2} \ln \left(\eta_{2} \mathrm{v}_{2}\right)+\mathrm{x}_{3} \ln \left(\eta_{3} \mathrm{v}_{3}\right)\right]$

where the letters have their usual significance

Grunberg and Nissan [26] putforward logarithmic relation between viscosity of binary mixtures and their pure components in equation (6).

$\ln \eta \operatorname{mix}=\mathrm{x}_{1} \ln \eta_{1}+\mathrm{x}_{2} \ln \eta_{2}+\mathrm{x}_{1} \mathrm{x}_{2} \mathrm{~d}$ 
on applying to ternary liquid mixtures this equation take up the following form (7).

$\ln \eta \operatorname{mix}=\mathrm{x}_{1} \mathrm{n} \eta_{1}+\mathrm{x}_{2} \ln \eta_{2}+\mathrm{x}_{3} \ln \eta_{3}+\mathrm{x}_{1} \mathrm{x}_{2} \mathrm{x}_{3} \mathrm{~d}$

where $d$ is constant regarded as a measure of strength of interaction between mixing component molecules.

Excess values of other parameter are calculated using the relation (8) [27].

$\mathrm{A}^{\mathrm{E}}=\mathrm{A}_{\mathrm{exp}}-\mathrm{A}_{\text {id }}$

$\mathrm{A}_{\mathrm{id}}=\Sigma \mathrm{xiAi}$, xi and $\mathrm{Ai}$ are the molefraction and parameters of the $\mathrm{i}^{\text {th }}$ component liquid.

All the calculated excess values were fitted to RedlichKister type polynomial equation (9).
$A^{E}=x_{1} x_{2} x_{3}\left[a+b x_{1}\left(x_{2}-x_{3}\right)+\left(c x_{1}^{2}\left(x_{2}-x_{3}\right)^{2}\right]\right.$

by the method of least square to derive the adjustable parameters a, b and c. From these a, b and $\mathrm{c}$ values theoretical values for all the excess parameter were calculated using the following relation (10) [27].

$\sigma=\left[\left(\mathrm{A}_{\exp }^{\mathrm{E}}-\mathrm{A}_{\mathrm{cal}}^{\mathrm{E}} /(\mathrm{n}-\mathrm{m})\right]^{1 / 2}\right]$

where $\mathrm{n}-$ is the number of measurements and $\mathrm{m}$ is the number of adjustable parameters. The values of a, b, c and $\sigma$ are given in the Table 4(a) \& 4(b).

Table - 2: Densities, viscosities and Excess parameters for the ternary mixture of Ethanol $+1,2$ Propanediol + Cyclohexanone at $308.15 \mathrm{~K}$

\begin{tabular}{|c|c|c|c|c|c|c|c|c|c|c|c|c|c|}
\hline $\mathbf{X}_{1}$ & $\mathbf{X}_{2}$ & $\mathbf{X}_{3}$ & $\begin{array}{c}\rho \\
\text { g.cm }\end{array}$ & $\begin{array}{c}\mathrm{V}^{\mathrm{E}} \\
\left(\mathrm{cm}^{3} \mathbf{m o l}^{-1}\right)\end{array}$ & $\begin{array}{c}\eta \\
(\mathbf{m P a} . s)\end{array}$ & $\underset{(\text { mpa.s) }}{\Delta \eta}$ & $\begin{array}{c}\Delta \ln \eta \\
(\mathbf{m p a} . \mathbf{s})\end{array}$ & d & $\underset{\left(\mathrm{cm}^{3} \mathrm{~mol}^{-1}\right)}{V_{\text {mix }}}$ & $\begin{array}{c}\mathrm{V}_{1} \\
\left(\mathrm{~cm}^{3} \mathbf{m o l}^{-1}\right)\end{array}$ & $\begin{array}{c}\mathbf{V}_{2} \\
\left(\mathrm{~cm}^{3} \mathbf{m o l}^{-1}\right)\end{array}$ & $\begin{array}{c}\mathrm{V}_{3} \\
\left(\mathrm{~cm}^{3} \mathrm{~mol}^{-1}\right)\end{array}$ & $\begin{array}{c}\Delta \mathrm{G}^{* \mathrm{E}} \\
\left(\mathrm{kJmol}^{-1}\right)\end{array}$ \\
\hline 0.104 & 0.1975 & 0.6985 & 0.9350 & -0.1074 & 1.6538 & -3.5706 & -0.7856 & -54.7630 & 94.4012 & 6.1703 & 14.6545 & 73.6528 & 11.4591 \\
\hline 0.2062 & 0.2946 & 0.4992 & 0.9335 & -0.1555 & 1.8373 & -5.2893 & -1.0191 & -33.6087 & 86.5967 & 12.2339 & 21.8594 & 52.6378 & 11.5021 \\
\hline 0.3007 & 0.3917 & 0.3076 & 0.9326 & -0.2164 & 2.2902 & -6.7417 & -1.2554 & -34.6517 & 79.1348 & 17.8406 & 29.0643 & 32.4346 & 11.7976 \\
\hline 0.3941 & 0.4851 & 0.1207 & 0.9323 & -0.3521 & 3.3161 & -7.5473 & -1.4817 & -64.2154 & 71.7542 & 23.3820 & 35.9946 & 12.7271 & 12.4152 \\
\hline 0.4514 & 0.1499 & 0.3937 & 0.8946 & -0.3081 & 1.2385 & -2.8879 & -0.5255 & -19.7261 & 79.1240 & 26.7817 & 11.1226 & 41.5134 & 10.4026 \\
\hline 0.6082 & 0.2013 & 0.1827 & 0.8757 & -0.3569 & 1.4287 & -3.6598 & -0.6110 & -27.3166 & 69.9326 & 36.0847 & 14.9365 & 19.2646 & 10.4466 \\
\hline 0.7014 & 0.2023 & 0.0963 & 0.8593 & -0.2807 & 1.4306 & -3.6508 & -0.5820 & -42.5989 & 66.4976 & 41.6142 & 15.0107 & 10.1542 & 10.3352 \\
\hline 0.8017 & 0.0954 & 0.0981 & 0.8309 & -0.2339 & 1.2467 & -1.6491 & -0.2464 & -32.8451 & 64.7523 & 47.5651 & 7.0787 & 10.3440 & 9.9628 \\
\hline 0.8913 & 0.0543 & 0.0541 & 0.8086 & -0.1620 & 1.1073 & -0.9361 & -0.1005 & -38.4141 & 62.4483 & 52.8811 & 4.0290 & 5.7045 & 9.6113 \\
\hline 0.7096 & 0.0986 & 0.1917 & 0.8502 & -0.2677 & 1.1968 & -1.8060 & -0.2900 & -21.6280 & 69.3662 & 42.1008 & 7.3161 & 20.2136 & 10.0264 \\
\hline 0.5037 & 0.199 & 0.2972 & 0.8913 & -0.2964 & 1.4036 & -3.6908 & -0.6446 & -21.6403 & 75.7018 & 29.8846 & 14.7658 & 31.3380 & 10.5862 \\
\hline 0.3079 & 0.2989 & 0.3931 & 0.9239 & -0.2458 & 1.7925 & -5.3793 & -0.9941 & -27.4809 & 81.6662 & 18.2678 & 22.1785 & 41.4501 & 11.3132 \\
\hline 0.1113 & 0.3939 & 0.5038 & 0.9515 & -0.1962 & 2.5133 & -6.6502 & -1.3328 & -60.3442 & 88.7796 & 6.6034 & 29.2275 & 53.1228 & 12.2692 \\
\hline 0.4026 & 0.4444 & 0.1529 & 0.9286 & -0.4605 & 3.2720 & -6.7736 & -1.3652 & -49.9073 & 72.5268 & 23.8863 & 32.9746 & 16.1224 & 12.4093 \\
\hline 0.2003 & 0.5086 & 0.2089 & 0.9592 & -0.3502 & 4.0667 & -7.2367 & -1.5952 & -74.9603 & 71.3072 & 11.8838 & 37.7383 & 22.0273 & 12.8643 \\
\hline 0.1092 & 0.6835 & 0.2072 & 0.9832 & -0.3864 & 6.0897 & -8.8579 & -2.1381 & -138.2580 & 78.6651 & 6.4788 & 50.7160 & 21.8480 & 14.0026 \\
\hline 0.1031 & 0.7005 & 0.1962 & 0.9849 & -0.3230 & 8.5011 & -6.7890 & -2.1873 & -154.3930 & 78.4676 & 6.1169 & 51.9774 & 20.6881 & 14.7540 \\
\hline 0.0592 & 0.8717 & 0.0692 & 1.0075 & -0.2152 & 12.002 & -6.7312 & -2.6806 & -750.7220 & 75.2771 & 3.5123 & 64.6805 & 7.29675 & 15.4419 \\
\hline 0.2077 & 0.6914 & 0.1008 & 0.9748 & -0.3368 & 6.6165 & -8.4497 & -2.1244 & -146.7610 & 73.9200 & 12.3229 & 51.3022 & 10.6287 & 14.0497 \\
\hline 0.3012 & 0.5021 & 0.1966 & 0.9440 & -0.2838 & 3.0936 & -8.1472 & -1.5629 & -52.5657 & 75.5794 & 17.8702 & 37.2560 & 20.7303 & 12.3754 \\
\hline 0.4085 & 0.2936 & 0.2979 & 0.9107 & -0.1961 & 1.9304 & -5.0952 & -0.9429 & -26.3906 & 77.2478 & 24.2364 & 21.7852 & 31.4118 & 11.3553 \\
\hline 0.5135 & 0.1829 & 0.3037 & 0.8886 & -0.2965 & 1.2865 & -3.4820 & -0.5963 & -20.9056 & 75.7741 & 30.4661 & 13.5712 & 32.0234 & 10.3908 \\
\hline 0.4012 & 0.1594 & 0.4414 & 0.9016 & -0.2657 & 1.1899 & -3.1558 & -0.5721 & -20.2676 & 81.9252 & 23.8033 & 11.8275 & 46.5431 & 10.3901 \\
\hline 0.2051 & 0.1994 & 0.5955 & 0.9265 & -0.2233 & 1.4229 & -3.7992 & -0.7542 & -30.9709 & 89.5585 & 12.1686 & 14.7955 & 62.7921 & 10.9984 \\
\hline 0.2033 & 0.1103 & 0.6863 & 0.9194 & -0.1806 & 1.3769 & -2.0628 & -0.5065 & -32.9178 & 92.4615 & 12.0618 & 8.1843 & 72.3664 & 10.9963 \\
\hline 0.1158 & 0.0873 & 0.7968 & 0.9260 & -0.1476 & 1.4229 & -1.5915 & -0.4742 & -58.8788 & 97.2539 & 6.87045 & 6.4777 & 84.0180 & 11.1854 \\
\hline 0.0565 & 0.0614 & 0.8821 & 0.9292 & -0.0999 & 1.4692 & -1.0507 & -0.4236 & -138.4480 & 100.8603 & 3.3521 & 4.5559 & 93.0124 & 11.3406 \\
\hline
\end{tabular}


Table - 3: Densities, viscosities and Excess parameters for the ternary mixture of Ethanol $+1,2$ Propanediol + Cyclohexanone at $318.15 \mathrm{~K}$

\begin{tabular}{|c|c|c|c|c|c|c|c|c|c|c|c|c|c|}
\hline $\mathbf{X}_{1}$ & $\mathbf{X}_{2}$ & $\mathbf{X}_{3}$ & $\begin{array}{c}\rho \\
\text { g.cm }\end{array}$ & $\begin{array}{c}\mathbf{V}^{\mathrm{E}} \\
\left(\mathrm{cm}^{3} \mathrm{~mol}^{-1}\right)\end{array}$ & $\begin{array}{c}\eta \\
\text { npa.s })\end{array}$ & $\underset{(\mathbf{m p a} . \mathbf{s})}{\Delta \eta}$ & $\underset{(\mathbf{m P a} . \mathbf{s})}{\Delta \ln \eta}$ & d & $\begin{array}{c}V_{\operatorname{mix}} \\
\left(\mathrm{cm}^{3} \mathrm{~mol}^{-1}\right)\end{array}$ & $\begin{array}{c}\mathrm{V}_{1} \\
\left(\mathrm{~cm}^{3} \mathbf{m o l}^{-1}\right)\end{array}$ & $\begin{array}{c}\mathrm{V}_{2} \\
\left(\mathrm{~cm}^{3} \mathrm{~mol}^{-1}\right)\end{array}$ & $\begin{array}{c}\mathrm{V}_{3} \\
\left(\mathrm{~cm}^{3} \mathrm{~mol}^{-1}\right)\end{array}$ & $\begin{array}{c}\Delta \mathrm{G}^{* \mathrm{E}} \\
\left(\mathrm{kJmol}^{-1}\right)\end{array}$ \\
\hline & & & & & & & & & & & & & \\
\hline & & 4992 & & & & & & & & & & & \\
\hline 0.3007 & 3917 & 3076 & 9259 & & .7247 & -3.8232 & -0.9363 & & & & & & \\
\hline 3941 & 4851 & 207 & 249 & & & & & & & & & & 665 \\
\hline 0.4514 & 0.1499 & 0.3937 & 8872 & 0.0100 & & -1.6419 & -0.2866 & & & & & & 10.0101 \\
\hline 6082 & 2094 & 0.1827 & 8684 & & 175 & -2.2114 & .3834 & & & & & & 090 \\
\hline 0.7014 & 0.2023 & 0.0963 & 8503 & & 2216 & -1.9964 & -0.3354 & 年. & & & & & 010 \\
\hline .8017 & 0954 & 0.0981 & 8212 & & 964 & -0.9387 & .0370 & & & & & & 122 \\
\hline 0.8913 & 0.0543 & 0.0541 & 7981 & -0.1881 & 0.9146 & -0.5189 & & 35.89056 & & & & & 728 \\
\hline 0.7096 & 0.0986 & 0.1917 & 8411 & -0.3008 & 0365 & -0.9682 & .0753 & .01431 & & & & & 97.2475 \\
\hline 0.5037 & 0.199 & 0.2972 & 0.8836 & -0.3489 & 1.0957 & -2.1423 & .3917 & -13.1498 & & & & & 10.0440 \\
\hline 0.3079 & 2989 & 0.3931 & 9172 & & 1827 & -2.9796 & .7036 & 195 & & & & & 992 \\
\hline 0.1113 & 0.3939 & 0.5038 & 0.9458 & 2312 & 9649 & -3.6745 & -1.0041 & -45.4651 & & & & & \\
\hline 0.4026 & 0.4444 & 0.1529 & 9211 & -0.5042 & 4448 & -3.6882 & .0339 & -37.7963 & & & & & 665 \\
\hline 0.2003 & 0.5086 & 0.2089 & 0.9532 & 4148 & 3.0394 & -3.8157 & .2542 & 8.9374 & & & & & 12.2181 \\
\hline 0.1092 & 6835 & 0.2072 & 9777 & -0.4437 & 4.6592 & -4.3522 & 7232 & 11.431 & & & & & 13.4082 \\
\hline 0.1031 & 0.7005 & 0.1962 & 9791 & 3603 & & -2.8185 & -1.7674 & & & & & & 209 \\
\hline 0.0592 & 0.8717 & 0.0692 & 1.0021 & & 9.3444 & -1.8793 & -2.2068 & -617.984 & 75.6857 & & & & 14.8864 \\
\hline 0.2077 & 0.6914 & 0.1008 & 0.9685 & -0.3859 & 4.5016 & -4.5729 & -1.7107 & & & & & & \\
\hline 0.3012 & 0.5021 & 0.1966 & 0.9373 & -0.3352 & 2.4044 & -4.4322 & -1.2102 & -40.7063 & & & & 20.8582 & 11.8200 \\
\hline 0.4085 & 0.2936 & 0.2979 & 0.9035 & -0.2367 & 1.4834 & -2.8873 & -0.6576 & -18.4070 & 77.8703 & 24.5943 & 21.9070 & 31.6057 & 10.7760 \\
\hline & 0.1829 & 0.3037 & 0.8808 & & 1.0335 & -2.0138 & -0.3485 & & & & & & 9.9141 \\
\hline 0.4012 & 0.1594 & 0.4414 & 0.8946 & -0.3046 & 0.9907 & -1.8175 & -0.3270 & -11.5841 & 82.5741 & .1548 & 8936 & 46.8303 & 9.9930 \\
\hline & 0.1994 & 0.5955 & & & & & & & & & & & 10.6201 \\
\hline 0.2033 & 0.1103 & 0.6863 & 0.9137 & -0.2388 & & -1.1151 & -0.2695 & & & & & & 10.6534 \\
\hline 0.1158 & 0.0873 & 0.7968 & 0.9204 & & & -0.9349 & & & & & & & 10.6436 \\
\hline 0.0565 & 0.0614 & 0.8821 & 0.9237 & -0.1117 & 1.1756 & -0.5884 & -0.1960 & -64.0620 & 101.4577 & 3.4016 & 4.58137 & 93.5864 & 10.8482 \\
\hline
\end{tabular}

Table - 4(a): Adjustable parameters a, b, c and $\sigma$ (standard deviation) values for the excess parameters at $308.15 \mathrm{~K}$

\begin{tabular}{|c|c|c|c|c|}
\hline Parameters & a & b & c & $\boldsymbol{\sigma}$ \\
\hline $\mathrm{V}^{\mathrm{E}}\left(\mathrm{g} \cdot \mathrm{cm}^{-3}\right)$ & -9.16208 & -20.9987 & -291.8910 & 0.0082 \\
\hline$\Delta \eta(\mathrm{mPa} . \mathrm{s})$ & -198.7270 & -938.7330 & -1209.7000 & 0.0812 \\
\hline$\Delta^{\mathrm{G} * \mathrm{E}}\left(\mathrm{kJ} \mathrm{mol}^{-1}\right)$ & 426627 & 447595 & 20.1745 & 0.6195 \\
\hline
\end{tabular}

Table - 4(b): Adjustable parameters a, b, c and $\sigma$ (standard deviation) values for the excess parameters at $318.15 \mathrm{~K}$

\begin{tabular}{|c|c|c|c|c|}
\hline Parameters & a & b & c & $\boldsymbol{\sigma}$ \\
\hline $\mathrm{V}^{\mathrm{E}}\left(\mathrm{g} . \mathrm{cm}^{-3}\right)$ & 10.6224 & -23.0984 & -331.289 & 0.0969 \\
\hline$\Delta \eta(\mathrm{mPa} . \mathrm{s})$ & -107.405 & -480.475 & -851.307 & 0.0489 \\
\hline$\Delta^{\mathrm{G} * \mathrm{E}}\left(\mathrm{kJmol}^{-1}\right)$ & 407083 & 395809 & 13.5242 & 0.5968 \\
\hline
\end{tabular}

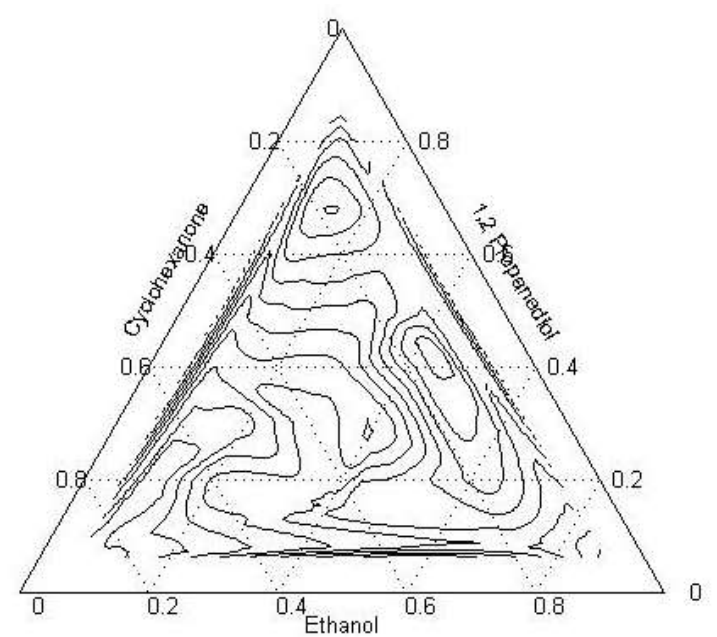

Fig - 1(a): 3D contour curves of Excess volume against with molefraction $\mathrm{x}_{1}, \mathrm{x}_{2}$ and $\mathrm{x}_{3}$ ternary mixtures of Ethanol $+1,2$ propanediol + cyclohexanone at $308.15 \mathrm{k}$ 


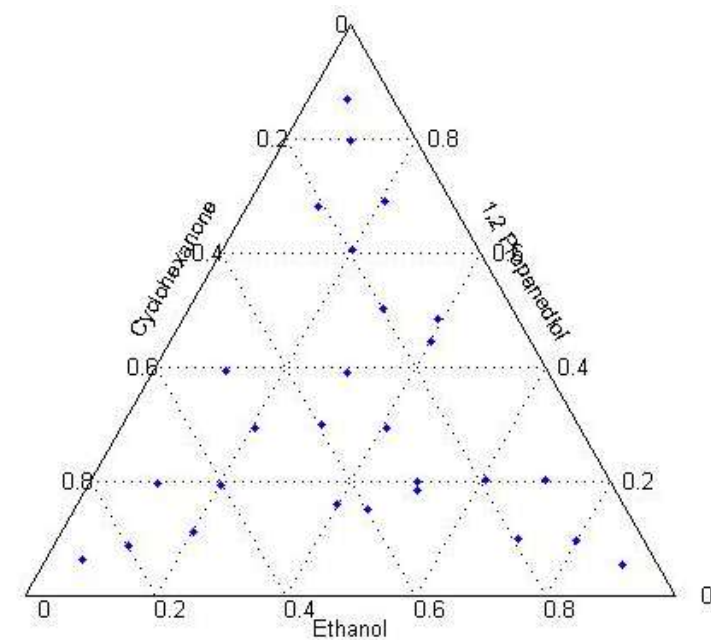

Fig - 1(b): 3D contour curves point of Excess volume against with molefraction $\mathrm{x}_{1}, \mathrm{x}_{2}$ and $\mathrm{x}_{3}$ ternary mixtures of Ethanol + 1,2-propanediol + cyclohexanone at 308.15k

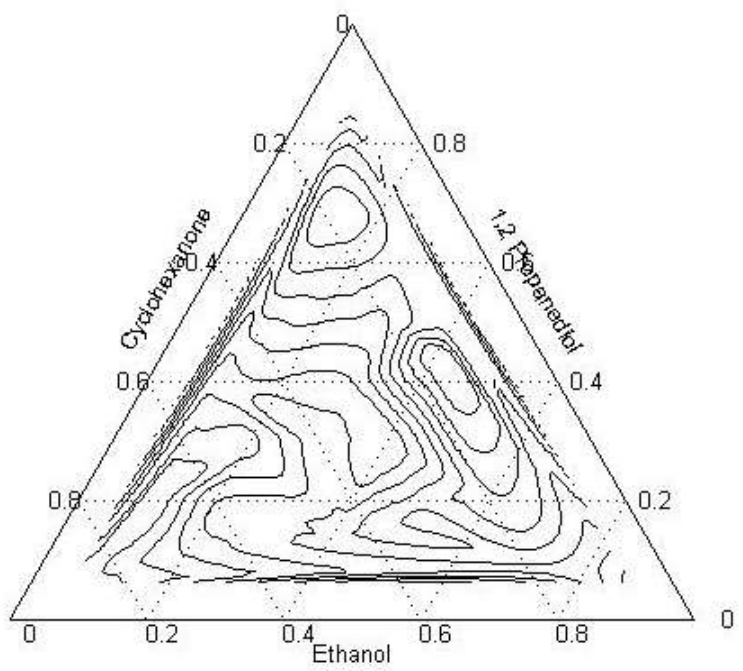

Fig - 2(a): 3D contour curves of Excess volume against with molefraction $\mathrm{x}_{1}, \mathrm{x}_{2}$ and $\mathrm{x}_{3}$ ternary mixtures of Ethanol $+1,2$ propanediol + cyclohexanone at $318.15 \mathrm{k}$

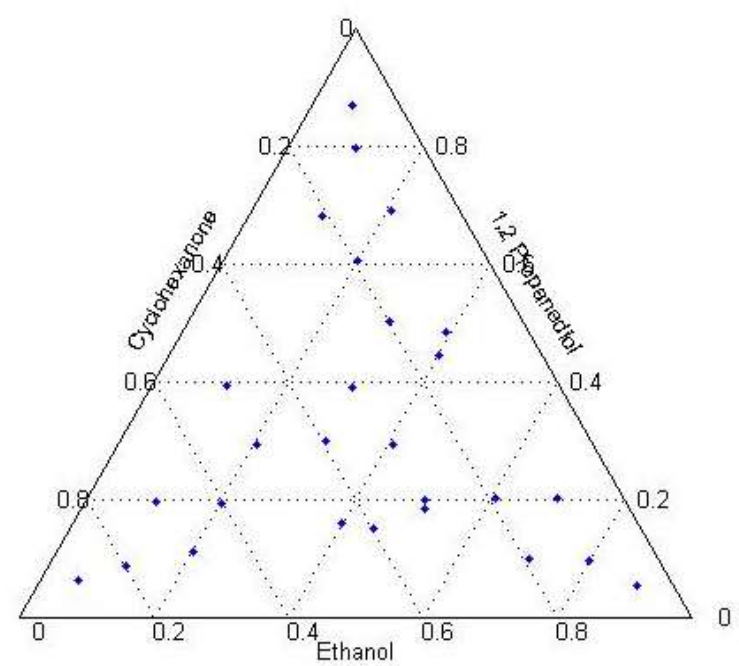

Fig - 2(b): 3D contour curves point of Excess volume against with molefraction $\mathrm{x}_{1}, \mathrm{x}_{2}$ and $\mathrm{x}_{3}$ ternary mixtures of Ethanol + 1,2-propanediol + cyclohexanone at 308.15k

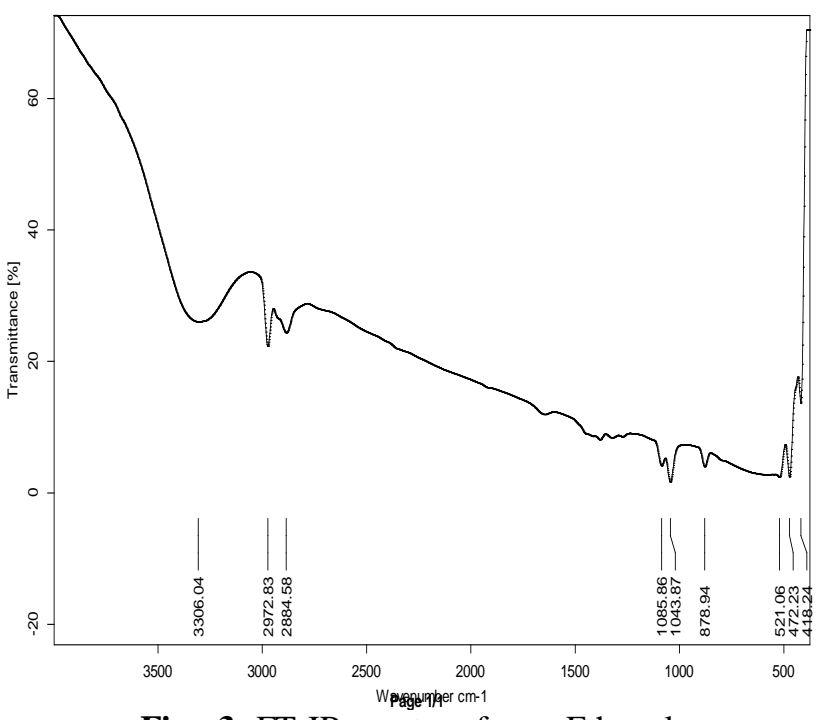

Fig - 3: FT-IR spectra of pure Ethanol

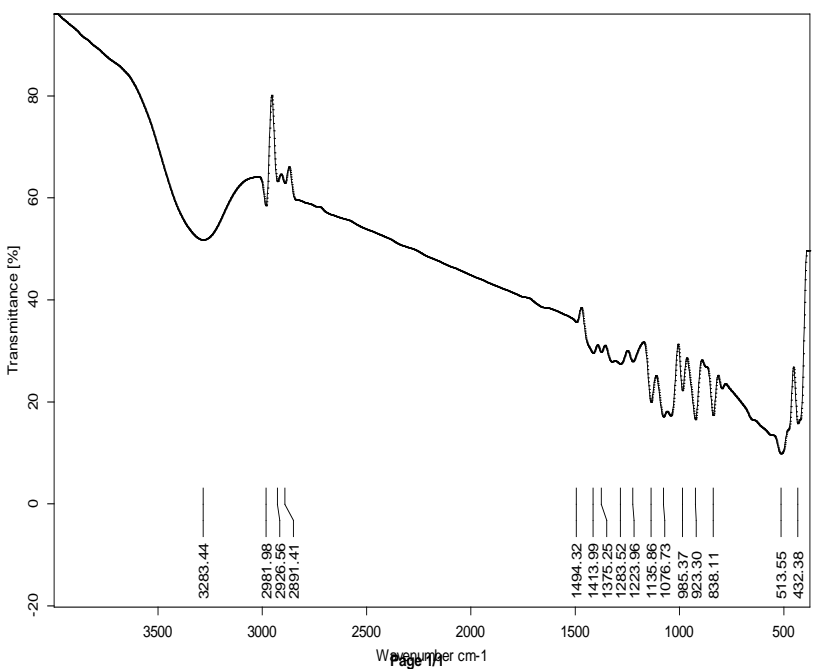

Fig - 4: FT-IR spectra of pure 1,2-propanediol

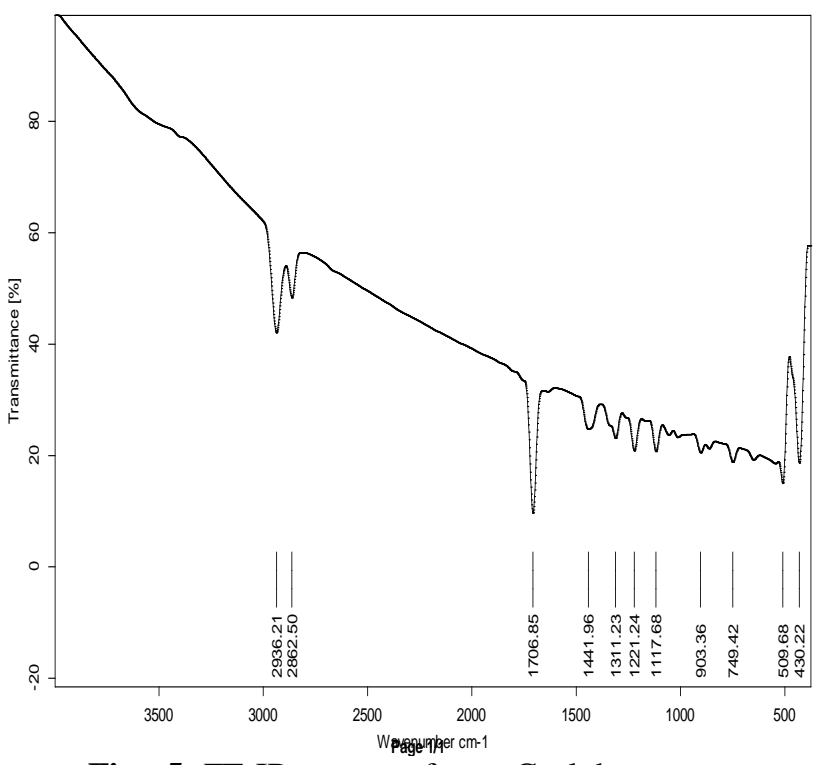

Fig - 5: FT-IR spectra of pure Cyclohexanone 


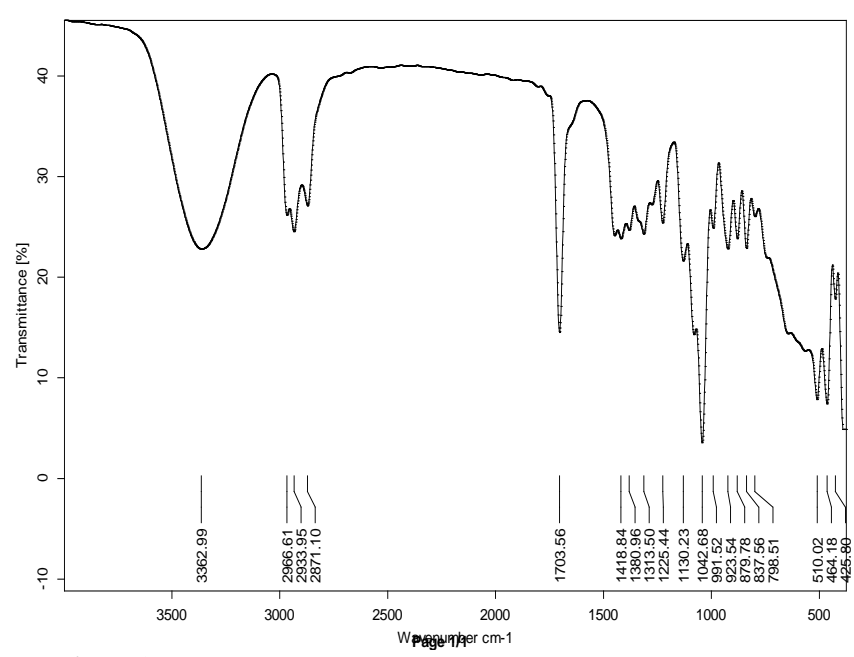

Fig - 6: Normalised FT-IR spectra of Ethanol + 1,2propanediol + cyclohexanone ternary mixtures at equimolar concentration.

The types of interaction taking place between the molecule in the given analysed ternay mixtures are discussed below on the basis of the values of Excess volume $\left(\mathrm{V}^{\mathrm{E}}\right)$, deviation in viscosity $(\Delta \eta)$ and Gibbs free energy of activation of viscous flow $\left(\Delta \mathrm{G}^{* \mathrm{E}}\right)$ which are presented in Table $2 \& 3$.

The important factors which influence the sign and magnitude of excess thermodynamic functions can be divided into physical, chemical and structural contributions.

1. Physical contribution comprises dispersion forces.

2. Chemical contribution includes charge transfer and formation of hydrogen bonds.

3. Geometrical fitting of component molecules into each other and structure also due to difference in size and shape of the molecules.

The factor (1) will contribute expansion in volume and $2 \&$ 3 factor will contribute contraction or reduction in volume. The actual value of Excess volume $\left(\mathrm{V}^{\mathrm{E}}\right)$ would be determined by the relative strength of the factor which were responsible for expansion and contraction.

As it can be seen from the Table $2 \& 3$, The excess volumes $\left(\mathrm{V}^{\mathrm{E}}\right)$ of the given ternary mixtures are negative for over all the entire composition range at 308.15 and $318.15 \mathrm{~K}$. The variation of excess volume $\left(\mathrm{V}^{\mathrm{E}}\right)$ are plotted against with respect to molefraction $\mathrm{x}_{1}, \mathrm{x}_{2}$ and $\mathrm{x}_{3}$ which are graphically represented in Figures 1 (a), 1 (b), 2 (a) and 2 (b). Negative $\mathrm{V}^{\mathrm{E}}$ values are observed by increasing the concentration of first component (1) Ethanol while the $\mathrm{V}^{\mathrm{E}}$ becomes more negative values when increasing the concentration of second component (2) (1,2-propanediol) and smaller negative $\mathrm{V}^{\mathrm{E}}$ values could be observed by increasing the concentration third component (3). (cyclohexanone). when compared to component 1 and 2 composition of range of the $\mathrm{V}^{\mathrm{E}}$ values will be higher magnitude of negative values than the third component (3) composition range. The negative values of $\mathrm{V}^{\mathrm{E}}$ prove that there is specific interaction like through hydrogen bond formation between the mixed components are stronger than the interaction between the pure components of molecules. It is like the hydrogen bond formation between Ehanol +1,2-propanediol are stronger than Ethanol - Ethanol and 1,2-propanediol - 1,2-propanediol i.e., $\mathrm{OH}$.... OH of Ethanol and 1,2-propanediol.

The excess volume of constitute binary mixtures is negative magnitude from measured data and the literature values are also negative magnitude because of all the three components are polar nature and the dipolemoment value 1.69D (1), 2.27D (2) and 3.01D (3). At near equimolar concentration, component $1\left[\mathrm{x}_{1}=0.3,0.4,0.3\right], 2\left[\mathrm{x}_{2}=0.3,0.3,0.4\right]$ and 3 $\left[\mathrm{x}_{3}=0.4,0.3,0.3\right]$ the component $(2) \mathrm{V}^{\mathrm{E}}$ value will be higher negative magnitude than the component 1 and 3 .

As the temperature is raised from $308.15 \mathrm{~K}$ to $318.15 \mathrm{~K}$ the excess volume $\left(\mathrm{V}^{\mathrm{E}}\right)$ will be decreased ie., more negative values. It suggest that hetero association occurs through Ethanol +1,2-propanediol + cyclohexanone. The interaction between Ethanol $+1,2$-propanediol is stronger than the interaction between 1,2-propanediol + cyclohexanone and ethanol + cyclohexanone. Because of both Ethanol and 1,2propanediol are self associated compounds and can easily associated through intermolecular hydrogen bonding formation between the molecules. In the case of cyclohexanone it exhilbits dipole-dipole interaction in pure state. So it can form weak association to Ethanol molecules. Therefore dipoledipole interaction H-bond formation are favorable for 1,2propanediol + cyclohexanone, and Ethanol + cyclohexanone.

From the excess volume $\left(\mathrm{V}^{\mathrm{E}}\right)$ observation, Ethanol + 1,2propanediol interaction are stronger than the Ethanol + cyclohexanone and 1,2-propanediol + cyclohexanone and there will be formation of cross complex between the Ethanol + 1,2-propanediol + cyclohexanone systems. The above attractive interactions are indicated by the contour triangle graphs.

Tables $2 \& 3$ show that the values of $\Delta \eta$ for the analysed ternary mixtures are negative over the entire composition range at 308.15 and $318.15 \mathrm{~K}$. According to Vogel and Weiss [28] mixtures with strong interaction between the molecules results in positive viscosity deviation $(\Delta \eta)$ where as for mixtures without strong interaction viscosity deviation are negative.

The present system under discussion 1,2-propanediol as the common component of the system of Ethanol $+1,2$ propanediol + cyclohexanone. By the observation of $\mathrm{V}^{\mathrm{E}}$, the breaking of hydrogen bonding in alkanol and 1, 2 propanediol, formation of hydrogen bonding between Ethanol and 1,2- propanediol, at the same time charge transfer occurs like dipole-dipole interaction between 1,2propanediol + cyclohexanone and Ethanol + cyclohexanone make the mixture is easily flow than the pure liquids. The value of $\Delta \ln \eta$ and $d$ also negative. This will indicate the presence of dispersion force arising in associated pure liquids. When temperature increased from 308. 15 to $318.15 \mathrm{~K}$, the $\Delta \eta$ values will become less negative.

The Gibbs free energy of activation of viscous flow $\left(\Delta \mathrm{G}^{* \mathrm{E}}\right)$ of ternary mixtures at both temperatures are presented in 
Table $2 \& 3$ over whole range of composition. According Reed and Tailor [29] the positive value of $\Delta \mathrm{G}^{* \mathrm{E}}$ may be due to specific interaction like hydrogen bond formation and charge transfer, where as negative values of $\Delta \mathrm{G}^{* \mathrm{E}}$ may be ascribed to dispersion force within the systems. The $\Delta \mathrm{G}^{* \mathrm{E}}$ values are positive over all concentration at both temperatures. In these system, the positive values of $\Delta \mathrm{G}^{* \mathrm{E}}$ decreased with increasing temperature from 308.15 to $318.15 \mathrm{~K}$. This would imply that there would be specific interaction like hydrogen bonding between component moleclues and dipole-dipole interaction among the Ethanol + 1,2-Propanediol + cyclohexanone molecules.

\section{HEAT OF MIXING}

The heats of mixing value of the given ternary system were measured with calorimeter. Generally heat of mixing of binary and ternary liquid mixture may be influenced by two factor such as (1) The absorption of heat [endothermic] due to the dissociation of self associated liquids. (ii) The second factor is the liberation of heat [Exothermic] as result of hydrogen bonding formation between the component molecules [30]. The heat of mixing value of the ternary mixture at near equimolar concentration is $-895 \mathrm{~J} / \mathrm{mol}$. The observation of $\mathrm{V}^{\mathrm{E}}, \Delta \eta \Delta \mathrm{G}^{* \mathrm{E}}$ and $\Delta H_{m i x}^{E}$ would predict that there is specific interaction between the component molecules.

\section{FT-IR SPECTRA}

FT-IR spectra of pure liquids of ethanol, 1,2-Propanediol, cyclohexanone and mixtures of Ethanol, + 1,2-propanediol + cyclohexanone at equimolar concentration are depicted in Figures (3,4,5 and 6). According to karunakar and srinivas [31] the intensity of an absorption in the IR spectrum is related to change in dipolemoment that occurs during the vibration. Consequently, vibration that (occur) produce large change in dipolemoment results in more intense absorption than those that result in a relatively modest change in dipole. Vibration that donot change in dipolemoment will show little or no absorption for this vibration. Furthur FT-IR spectra has been used extensively to study intermolecular and intramolecular hytrogen bonding interaction between the component molecules. Usually intermolecular hydrogen bonding gives rise to broad bands, where as intramolecular hydrogen bonds appears sharp bands. In aliphatic alkanols shows the band appears at $3650 \mathrm{~cm}^{-1}$ which is due to free$\mathrm{OH}$ group in their pure state.

Pure Ethanol exhibits peak of $3306.04 \mathrm{~cm}^{-1}$ and 1,2propanediol exhibits $3283.44 \mathrm{~cm}^{-1}$, no-OH peak can be observed for cyclohexanone. when Ethanol is mixed with 1,2- propanediol and cyclohexanone mixture the absorption is shifted to longer wave number caused by strong intermolecular interaction like hydrogen bonding between $\mathrm{OH}$ group of Ethanol and $\mathrm{OH}$-group of 1,2-propanediol. It is clearly observed, the mixtures peak at $3362.99 \mathrm{~cm}^{-1}$ and the spectrum is broad. This contention was supported by the formation of intermolecular hydrogen bonding between the component molecules.

\section{CONCLUSION}

The densities and viscosities for ternary liquid mixtures of Ethanol and 1,2-propanediol with cylohexanone are determined experimentally, at 308.15 and $318.15 \mathrm{~K}$ over whole composition range. The value of $\mathrm{V}^{\mathrm{E}}, \Delta \eta$ and $\Delta \mathrm{G}^{* \mathrm{E}}$ are calculated from experimental results at both temperatures. The excess, deviation function are fitted to Redlich-kister type polynomial equation and corresponding standard deviations are calculated. The observed negative value of $\mathrm{V}^{\mathrm{E}}$, $\Delta \eta$ and the positive values of $\Delta \mathrm{G}^{* \mathrm{E}}$ for the given analysed ternary mixtures having the following conclusions may be drawn.

1. The negative magnitude of $\mathrm{V}^{\mathrm{E}}$ values suggest that intermolecular hydrogen bonding and dipole-dipole interaction between the molecules. This kind of interaction increasing with increasing temperature.

2. The $\Delta \eta$ values predicts the given mixtures is less viscous and greater fluidity than that of corresponding pure liquids.

3. $\Delta \mathrm{G}^{* \mathrm{E}}$ values reveals that there would be specific interaction between the conponent molecules.

4. The negative values $\mathrm{H}_{\text {mix }}^{\mathrm{E}}$ indicates attractive interaction among of unlike molecules.

5. FT-IR spectra reveals the formation of intermolecular hydrogen bonding between the component liquids.

\section{ACKNOWLEDGEMENTS}

The authors express, sincere gratitude to management of St. Joseph's College (Autonomous), Tiruchirappalli for providing necessary lab facilities. Also we thank to Asst. Professor J. Arockkiya Jayakumar and A. Sebastian, Research scholar in the department of mathematics St. Joseph's College, who helped in drawing 3-D contour diagrams.

\section{REFERENCES}

[1]. K. Sreenivasulu, V. Kovinda, P. Venkatsswaralu, K. Sivakumar, J. therm. Anal. Calorim. 115, 1805-1811 (2014)

[2]. Z. Nan, ZC Tan, J. therm. Anal. Calorim. 87, 539-544 (2007)

[3]. L. Venkatramana, K. Sreenivasulu, K. Sivakumar, K. Dayananda Reddy. k, J. therm. Anal. Calorim. 115, 1829-1834 (2014)

[4]. G.A. Krestov, "Thermodynamics of solvation", Ellis Harwood, England, 1991

[5]. IR. Radovic, MLJ. Kijevanin, AZ Tasic, SP. Serbanovic, BD. Djord Jervic, J. Fluid phase equalib. 298, 117-130 (2010)

[6]. I. Vogel. "Text book of organic chemistry" Wiley, New York, 1989 
[7]. JA. Riddik, WB Bunger, TK. Sakano, Tecnique of chemistry "Organic solvents" physical properties and method of purification, Wiley, New York, 1986

[8]. A. Hossein Zarei. J. Mol liq. 124, 23-31 (2006)

[9]. Mehdi Hasan, P. Apoorva, Hirray, B. Ujjan, Kadam, F. Dinesh, Swant, Keshav, Kurhe, B. Arun, Swant, J. Soln Chem. 40, 415-429 (2011)

[10]. M. Rui Pires, F. Henrique, Costa, Abel G.M, Ferriera, MA. Isabel, Fonseca, J. Chem Eng data. 52, 1240-1245 (2007)

[11]. MA. Motin, M.H. Kabir, ME. Huque, J. Phy. Chem liq. 43, 123-137 (2005)

[12]. A. Hossein zarei, Narjes Mirhidari, Zinab Zangeneh, J. Chem Eng data. 54, 847-854 (2009)

[13]. Mehrdad moosavi, Ahamud motahari, Abdollah omrani, Abbas Ali Rostami, Themocimica Acta. 561, $1-13$ (2013)

[14]. Quen-Shengli, Ming-Gaosu, Shuiwang, J. Chem Eng data 48, 1529-1539 (2003)

[15]. John George, V. Nandhibala, Sastry, J. Chem Eng data. 48, 1529-1539 (2003)

[16]. S. Thirumaran, J. Ramesh, Rasayan. J. Chem. 3, 733739 (2009)

[17]. A. Rose venis, X. Rosario Rajkumar, Orient J. Chem. 27, 105-111 (2011)

[18]. M. Srilakshmi, R. Ramesh Raju, C. Rambabu, GV. Rama Rao, K. Narendra, RRJC. 2, 24-31 (2013)

[19]. S.K. Md. Nayeem, M. Kondaiah, K. Sreekanth, D. Krishna Rao, J. thermodyn. 1-13 (2014)

[20]. B.K. Rout, SK. Dash, V. Chakravorty, D. Behra, Indian. J. Tech. 31, 745-753 (1993)

[21]. N. Swain, V. Chakravorty, Indian J. Chem. 35A, 395404 (1994)

[22]. X. Rosario Rajkumar, K.V. Raman, S.J. Arul Raj, Proc. Indian Acad Sci. (Chem. Soc) 90, 417-426 (1981)

[23]. T.M. Aminabhavi, LS. Manjeswar, C.B. Haligudi R.H. Balundgi, Indian J. Chem. 28A, 217-228 (1989)

[24]. C. Leppla, EN. Rezanova, Lichtendhaler, N. Rudigen, J. Chem Eng data. 45, 1019-1021 (2000)

[25]. N. Swain, Chakravorty, SK. Singh, D. Pandey Indian J. Chem. 38A, 1116-1127 (1999)

[26]. L. Grunberg, AH. Nissan, Nature. 164, 799-815 (1949)

[27]. L. Narashimha Rao, L. Venkatramana, C. Prabhavathi, K. Sivakumar, R.L Gardas, J. Therm. Anal Calorim. 123, 881-890 (2016)

[28]. H. Vogel, A. Weiss, Berbuns, Phy. Chem. 86, 193-205 (1982)

[29]. T.M. Reed III, Tailor, J. Phy. Chem liq. 63, 58-67 (1959)

[30]. A. Hossein Zarei, J. Chem Eng data. 51, 1597-1601 (2006)

[31]. T. Karunakar, C.H. Srinivas, RRJ of pure and apply. Physics. 1, 5-10 (2013)

\section{BIOGRAPHIES}

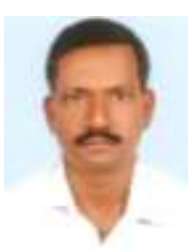

I. Johnson, author of this research Article. has got 15 years teaching experience in chemistry and guided many M.Sc., and M.Phil students for their project work. I worked as an assistant Professor of chemistry at St. Joseph's College Tiruchirappalli.

E.mail.id: johnson200672@gmail.com

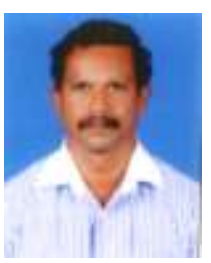

Dr. A Rosevenis is working as an Associate Professor in the Department of chemistry in St. Joseph's College - Tiruchirappalli. He has 17 years of teaching experience and guide many M.Phil scholar, and published many research articles. Now, eight Ph.D Students are doing Ph.D under his guidance.

\section{E.mail.id: rosevenis@gmail.com}

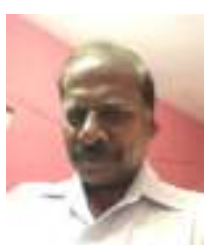

Dr. X. Rosario Rajkumar is the guide of Author-1. He worked as a Reader and former Head of the Department of chemistry At St. Joseph's College, Tiruchirappalli. He had 37 years teaching experience. He produced two Ph.D. students and guided many M.Phil.-scholar and has published many articles in reputed journals. E.mail.id: rosariorajkumar@gmail.com 